\title{
Interventions as an alternative to penalties in preventable readmissions
}

\author{
Andres Garcia-Arce , Jose L. Zayas-Castro \\ College of Engineering, University of South Florida, Tampa, FL, USA
}

Received: January 23, 2015

Accepted: March 31, 2015

Online Published: April 28, 2015

DOI: $10.5430 /$ jha.v4n $3 p 70$

URL: http://dx.doi.org/10.5430/jha.v4n3p70

\begin{abstract}
While expenditures in healthcare in the United States are the highest in the world, it is widely known that those resources are not being used efficiently. The government addressed this situation in the Patient Protection and Affordable Care Act, in an attempt to improve quality and affordability of healthcare. In the fiscal year 2013, the Centers for Medicare and Medicaid Services began imposing financial penalties through the Inpatient Prospective Payment System to hospitals that have higher than expected readmission rates for specific diseases. The nature and effects of this new policy have raised several concerns. This article discusses Medicare's hospital readmissions reduction program and presents an alternate policy based on diseasespecific interventions to reduce preventable readmissions. Our results show that a policy based on implementing disease-specific interventions, instead of penalties, may save $33.43 \%$ of hospitals from being under the penalization level in the first year, while at the same time improving the delivery of care.
\end{abstract}

Key Words: Disease-specific interventions, Readmissions, Medicare

\section{INTRODUCTION}

Over the last four years, the United States (US) spent on average $17.74 \%$ of its gross domestic product (GDP) on healthcare, the highest in the world. This is more than twice the rate of other high-income countries which was $7.78 \% .^{[1]}$ However, this high expenditure has not translated into a better quality. To illustrate, in 2001 the performance of the US healthcare system was ranked $37^{\text {th }}$ and in 2014 it was classified $46^{\text {th }}$ in efficiency. ${ }^{[2,3]}$ Furthermore, in 2012 the Institute of Medicine estimated that $30 \%$ of the total expenditures in 2009 on healthcare were wasted. ${ }^{[4]}$ In summary, the US healthcare system continues to face significant challenges in performance, quality and cost.
It has been argued that preventable readmissions are evidence of the deficiency in the quality of care, ${ }^{[5,6]}$ generating potential harm to patients and unnecessary costs. ${ }^{[7]}$ Much and varied research has been done to identify the causes of readmissions, their validity, and their interaction when predicting the risk of readmissions. ${ }^{[8,9]}$ Furthermore, preventable readmissions affect the Medicare-covered population. In fact, Jencks et al. in 2009 estimated that between 2003 and 2004, $19.6 \%$ of patients were unexpectedly readmitted, representing in 2004 a cost of $\$ 17.4$ billion. ${ }^{[10]}$ The Robert Wood Johnson Foundation in 2013 estimated that readmissions represent $\$ 26$ billion for Medicare, of which $\$ 17$ billion is estimated as the cost of avoidable readmissions. ${ }^{[11]}$

\footnotetext{
*Correspondence: Andres Garcia-Arce; Email: andresg@mail.usf.edu; Address: College of Engineering, University of South Florida, 4202 E. Fowler Avenue, ENB118, Tampa, FL 33620, USA.
} 
The US began a reform process promising a better, and less costly, healthcare system. ${ }^{[12]}$ The Patient Protection and Affordable Care Act (ACA) established that payments to eligible hospitals will be adjusted as an incentive to reduce readmissions. Therefore, the Centers for Medicare and Medicaid Services (CMS) started the hospital readmission reduction program (HRRP) which includes a set of economic penalties through the inpatient prospective payment system (IPPS) to hospitals that show excessive readmissions in certain diseases. However, imposing financial penalties to incentivize hospitals in reducing preventable readmissions has raised concerns such as the appropriateness of the policy or the possible undesired effects to hospitals.

This study explores the feasibility and preliminary effects of a disease-specific intervention as an alternative to HRRP. The goal is to decrease readmissions and reduce cost while directly improving the quality of care.

First, a review of literature is done to prove the plausibility of the assumption that interventions reduce the amount of preventable readmissions. Secondly, a different review is conducted to describe the available results of interventions in one specific disease. Then, using the data available from CMS, a simulated case is proposed and results from it are calculated. Finally, the simulation results are studied and compared with the available results from the current HRRP policy.

\section{BACKGROUND}

\subsection{Inpatient prospective payment system}

The IPPS, introduced in section 1886 (d) of the Social Security Act, is used by Medicare to reimburse hospitals for inpatient care services provided to covered patients. In the IPPS, the reimbursement calculation depends mainly on the diagnosis of the admission (not procedures), represented by the diagnosis related group (DRG) weight. The calculation of this payment is shown in Equation 1.

$$
D R G_{\text {weight }}(i, j)=(\text { Labor } \times W I F(j)+N o n L a b o r) \times D R G_{\text {weight }}(i), \forall i \in I, \forall j \in J
$$

Where $I$ and $J$ represent the set of providers and hospitals considered in IPPS, respectively. $D R G_{\text {weight }}(i)$ is a weight that accounts for the differences among the $i$ diseases in terms of resources and procedures. The WIF $(j)$ term accounts for the socioeconomical differences in each geographic location, and the labor and non-labor wage relates to the different portions of expenses related to the medical service provided. Medicare also adjusts for factors such as longer stays, disproportionate care hospital, indirect medical education, etc. The payment before adjustment is referred here as DRG base payment $\left(D R G_{\text {base }}(i, j), \forall i \in I, \forall j \in J\right)$.

\subsection{Calculations for the excess of readmissions}

The next element considered in the HRRP is excess of readmissions for the following conditions: acute myocardial infarction (AMI), heart failure (HF) and pneumonia (PN). The excess is calculated using patient-level administrative data for three years. The application of HRRP for FY2013 uses data from FY2009, FY2010 and FY2011. A hierarchical logistic regression is implemented to account for the average effect among hospitals, offering a risk adjustment approach. The expected readmissions measure, the denominator, is obtained by regressing the specific patient-level data using the average intercept while the numerator is obtained using the average intercept and the specific "residual" for each hospital (42 C.F.R. $\$ 412.150$ - §412.154).

Published by Sciedu Press

\subsection{Hospital readmission reduction program (HRRP)}

In the IPPS final rule for FY2013, an adjustment factor (AF) is applied to all reimbursements billed to Medicare from hospitals that present an excess of readmissions for AMI, HF and PN. ${ }^{[13]}$ In FY2015, total knee arthroplasty (TKA), total hip arthroplasty (THA) and congestive obstructive pulmonary disease (COPD) are included in the calculations of the HRRP. The AF depends on the DRG base payment for each specific disease (AMI, HF and PN in FY2013), the number of cases in the period considered, the payments for all admissions made in the period and the excess of readmissions for AMI, $\mathrm{HF}$ and PN (see Equation 2).

This AF affects the total payment for all admissions billed to Medicare through IPPS during the fiscal year. The implementation of the AF considers a ceiling adjustment of $1 \%$ for FY2013, which was raised to 2\% by FY2014 and 3\% for FY2015 (w/o quotations).

From the beginning the methodology, effects and results of HRRP policy attracted criticism. Some of the concerns relate to the inappropriateness of the nature of the incentive, ${ }^{[14]}$ the impact on the most vulnerable hospitals ${ }^{[15]}$ or the adjustments of payments applied to all diseases based on a small portion of them. ${ }^{[16]}$ Also, it is unclear whether the reduction in the payments to hospitals will improve the quality of care. 


$$
\operatorname{Adj.Factor}(j)=1-\frac{\sum_{i \in I}\left\{[\operatorname{Excess}(i, j)-1] \times D R G_{\text {base }}(i, j) \times N O C(i, j)\right\}}{D R G_{\text {all admissions }}(j)}, \forall j \in J
$$

Where Adj.Factor(j) represents the final adjustment applied to reimbursements, $\operatorname{Excess}(i, j)$ is the ratio calculated by CMS, $D R G_{\text {(all admissions) }}(j), \forall j \in J$ represents the payments for all of the admissions for each specific hospital during the period, and $N O C(i, j)$ is the number of cases of each disease by hospital.

\subsection{Interventions}

Joynt \& Jha in 2012 suggest that through holistic approaches, better financial and clinical outcomes can be achieved. ${ }^{[17]}$ The literature over the last two decades shows examples of improvement in quality of care and reduction in readmissions from interventions. ${ }^{[18,19]}$ As an illustration, we screened three scientific databases for systematic literature reviews that compile clinical trials of these interventions on patients with HF. This condition was selected since it is linked with the biggest readmissions rate for Medicare patients. Table
1 shows that disease-specific interventions appear to reduce readmissions (281 randomized trials or 64\%), thus our analysis builds on this assumption.

Naylor et al., in 2004 concluded that interventions improving the transition of care in elderly patients would bring better clinical and financial outcomes. ${ }^{[20]}$ Moreover, Hernandez et $a l$., in 2010 found that early follow-up procedures among HF patients lowered their risk of being readmitted. ${ }^{[21]}$ The documented interventions focus mainly in the discharge process, follow-up process and the transition of care. ${ }^{[20-25]}$ A review of the literature presenting results of interventions on $\mathrm{HF}$ patients is conducted (see Table 2). One of the conclusions from the review is that interventions to reduce readmissions in HF patients do not only improve the desired outcome, but also (in some cases) generate savings. Based on these results, a scenario where an intervention is applied to HF patients is simulated.

Table 1. Literature screening results supporting our assumptions

\begin{tabular}{|c|c|c|c|c|c|c|}
\hline Authors & Analysis & Timeframe & Subjects & Intervention & No of studies & Conclusion \\
\hline $\begin{array}{l}\text { Holland et al., } \\
2005^{[31]}\end{array}$ & $\begin{array}{l}\text { Systematic } \\
\text { Literature Review. }\end{array}$ & $\begin{array}{l}\text { Origin to June } \\
1,2004\end{array}$ & Patients with HF. & $\begin{array}{l}\text { Multidisciplinary } \\
\text { interventions. }\end{array}$ & 74 RCT & $\begin{array}{l}\text { Reductions in mortality } \\
\text { and admissions. }\end{array}$ \\
\hline $\begin{array}{l}\text { Jovicic et al., } \\
2006^{[32]}\end{array}$ & $\begin{array}{l}\text { Systematic } \\
\text { Literature Review. }\end{array}$ & $\begin{array}{l}\text { Origin to Nov. } \\
2005\end{array}$ & Patients with HF. & $\begin{array}{l}\text { Self-Management } \\
\text { Interventions. }\end{array}$ & $6 \mathrm{RT}$ & $\begin{array}{l}\text { Decreased overall } \\
\text { hospital readmissions and } \\
\text { readmissions for heart } \\
\text { failure. }\end{array}$ \\
\hline $\begin{array}{l}\text { Phillips et al., } \\
2004^{[33]}\end{array}$ & Meta-Analysis. & $\begin{array}{l}\text { Until Oct. } \\
2003\end{array}$ & Patients with CHF. & $\begin{array}{l}\text { Comprehensive } \\
\text { discharge planning plus } \\
\text { post discharge support. }\end{array}$ & $18 \mathrm{RT}$ & $\begin{array}{l}\text { Significant reduction in } \\
\text { readmissions. }\end{array}$ \\
\hline $\begin{array}{l}\text { Roccaforte et al., } \\
2005^{[34]}\end{array}$ & Meta-Analysis. & Until 2004 & Patients with HF. & $\begin{array}{l}\text { Disease Management } \\
\text { programs. }\end{array}$ & $33 \mathrm{RT}$ & $\begin{array}{l}\text { Reductions in mortality } \\
\text { and admissions. }\end{array}$ \\
\hline
\end{tabular}

\section{MeTHODS}

In the proposed simulated scenario, an intervention is applied to all HF admissions under the IPPS of Medicare. The effects on the AF, as well as the costs, are analyzed to compare the results of implementing this disease-specific intervention with HRRP.

\subsection{Simulated intervention}

The intervention used in the simulated scenario consists on a single follow-up call for HF patients, made by a registered nurse. The provider checks with the patient or caregiver the adherence to the discharge plan, listens to any change in patient condition or new symptoms, adjusts the medications and suggests visit/s to the hospital as necessary. The intervention is planned to take one hour (30 min preparation, planning and recording results, and another $30 \mathrm{~min}$ of direct communication with the patient). The direct cost of the intervention is based on the time spent by the nurse. The mean annual and hourly wages for a registered nurse is $\$ 67,930$ and $\$ 32.66$ respectively; ${ }^{[26]}$ therefore, the cost of the intervention is estimated at $\$ 32.66$. The effectiveness of the follow-up call made to HF patients is estimated using the actual reduction results published for similar interventions and included in Table 2. A triangular distribution is fitted to the data compiled from these cited interventions, resulting in a mean effectiveness, i.e., reduction on 30-day preventable readmissions, of $35.8 \%$. 
Table 2. Literature summary of interventions on HF patients

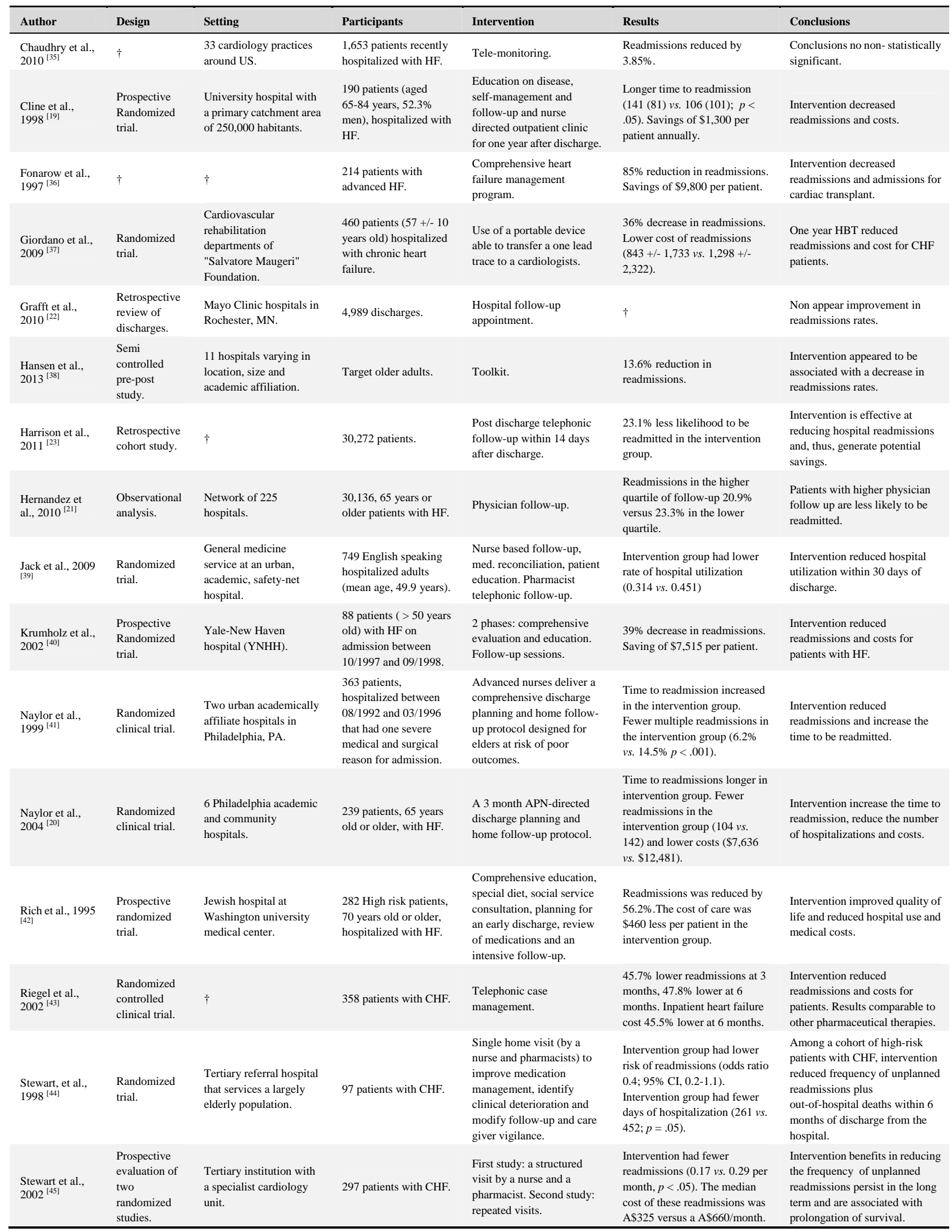

Note. ${ }^{\dagger}$ Not explicitly mentioned in the study 


\subsection{Data}

The data used to study the effect of the simulated intervention comes mainly from public use files (PUF) from repositories available on the CMS website. Specifically, we used the hospital readmissions reduction programs supplemental data file and the Inpatient Medicare Provider Utilization and Payment Data for IPPS FY2013 final rule. ${ }^{[27]}$ The number of hospitals considered was 3,500 .

\subsection{Procedure}

The data contains the number of cases and excess readmissions for AMI, HF and PN, by provider and the AF for each hospital, considering the adjustment ceiling of $1 \%$ for FY2013. Then, it follows that to calculate AF we only need the base payment for each specific condition and the total payments for all admissions. However, in this study there was no access to the total payment for all admissions. In- stead, we used the DRG, WIF, Labor and non-labor wages to calculate the base payment for each HRRP condition, and having the AF we use both quantities to estimate the total payments for the period. Finally, the excess of readmissions for HF after the intervention is calculated, and the AF is updated.

\section{RESUlTS}

\subsection{Base payments}

Using the described data, the base payments for the conditions considered by HRRP are calculated for each provider. The labor and non-labor wage for FY2013 were \$3,679.95 and $\$ 1,668.81$ respectively. The last two components are the WIF (specific for each hospital) and the DRG weights for each specific diagnosis. Table 3 shows the DRG weights considered in these calculations. The average payment, before the inclusion of the DRG weight, is $\$ 6,431.92$.

Table 3. DRG codes and weight for IPPS final rule FY2013

\begin{tabular}{|c|c|c|c|}
\hline Code & Description & Weight & Average DRG base payment \\
\hline 280 & Acute myocardial infarction with multiple comorbidities & 1.799 & $\$ 11,576.81$ \\
\hline 281 & Acute myocardial Infarction with comorbidities & 1.096 & $\$ 7,050.03$ \\
\hline 282 & Acute myocardial Infarction without comorbidities or multiple comorbidities & 0.773 & \$ 4,975.73 \\
\hline 291 & Heart failure with multiple comorbidities & 1.517 & \$ $9,759.80$ \\
\hline 292 & Heart failure with comorbidities & 1.003 & $\$ 6,453.79$ \\
\hline 193 & Pneumonia with multiple comorbidities & 1.489 & $\$ 9,579.06$ \\
\hline 194 & Pneumonia with comorbidities & 0.999 & $\$ 6,429.35$ \\
\hline 195 & Pneumonia without comorbidities or multiple comorbidities & 0.707 & $\$ 4,552.51$ \\
\hline
\end{tabular}

Using the described data, the base payments for the conditions considered by HRRP are calculated for each provider. The labor and non-labor wage for FY2013 were \$3,679.95 and $\$ 1,668.81$ respectively. The last two components are the WIF (specific for each hospital) and the DRG weights for each specific diagnosis. Table 3 shows the DRG weights considered in these calculations. The average payment, before the inclusion of the DRG weight, is $\$ 6,431.92$.

\subsection{DRG base payment for all discharges}

After the DRG base payments for each condition and for each hospital is obtained, the DRG base payment for all admissions by each hospital is computed. Results of the DRG payments for all admissions present big differences (see Table 4 , showing wide variation among the hospitals serving Medicare populations).

\subsection{Results from the simulated scenario}

The intervention was applied to the 1,193,210 admissions for HF reported to Medicare through IPPS in FY2013. Results show that after the intervention, 710 hospitals were freed from penalization, representing a decrease of $33.43 \%$ (see Table 5). The average AF also improved from 0.0042 to 0.0039

Table 4. Descriptive statistics for DRG all admission payments

\begin{tabular}{ll}
\hline Measurement & Value \\
\hline Max & $\$ 711,552,145.07$ \\
Mean & $\$ 1,616,546.71$ \\
Min & $\$ 70,208,431.47$ \\
St Dev. & $\$ 72,055,027.96$ \\
\hline
\end{tabular}

Figure 1 shows the AF before and after the intervention for 150 providers randomly selected from the 3,500 initially considered. The behavior of the AFs was not homogeneous. Some hospitals experienced high improvement (i.e. provider 46), medium (i.e. provider 42), or no improvement (i.e. provider 63). Additionally, there are hospitals that after im- 
plementing the intervention were free from penalizations (i.e. provider 49), whereas others improved less and were unable to avoid the penalties (i.e. provider 72).

The intervention had a total cost of $\$ 38.9 \mathrm{M}$, while the total amount of penalties was $\$ 253.3 \mathrm{M}$. Comparing these simulated results with the actual HRRP results for the same period, a decrease of $\$ 26.7 \mathrm{M}$ is observed (HRRP penalties in FY2013 were $\$ 280 \mathrm{M})$.
Table 5. Hospitals being penalized before and after the intervention

\begin{tabular}{llll}
\hline & $\begin{array}{l}\text { Hospitals } \\
\text { Penalized }\end{array}$ & \% of the total & $\begin{array}{l}\text { Average } \\
\text { adjustment factor }\end{array}$ \\
\hline $\begin{array}{l}\text { Before } \\
\text { Intervention }\end{array}$ & 2,124 & 60.69 & 0.0042 \\
$\begin{array}{l}\text { After } \\
\text { Intervention }\end{array}$ & 1,414 & 40.40 & 0.0039 \\
\hline
\end{tabular}

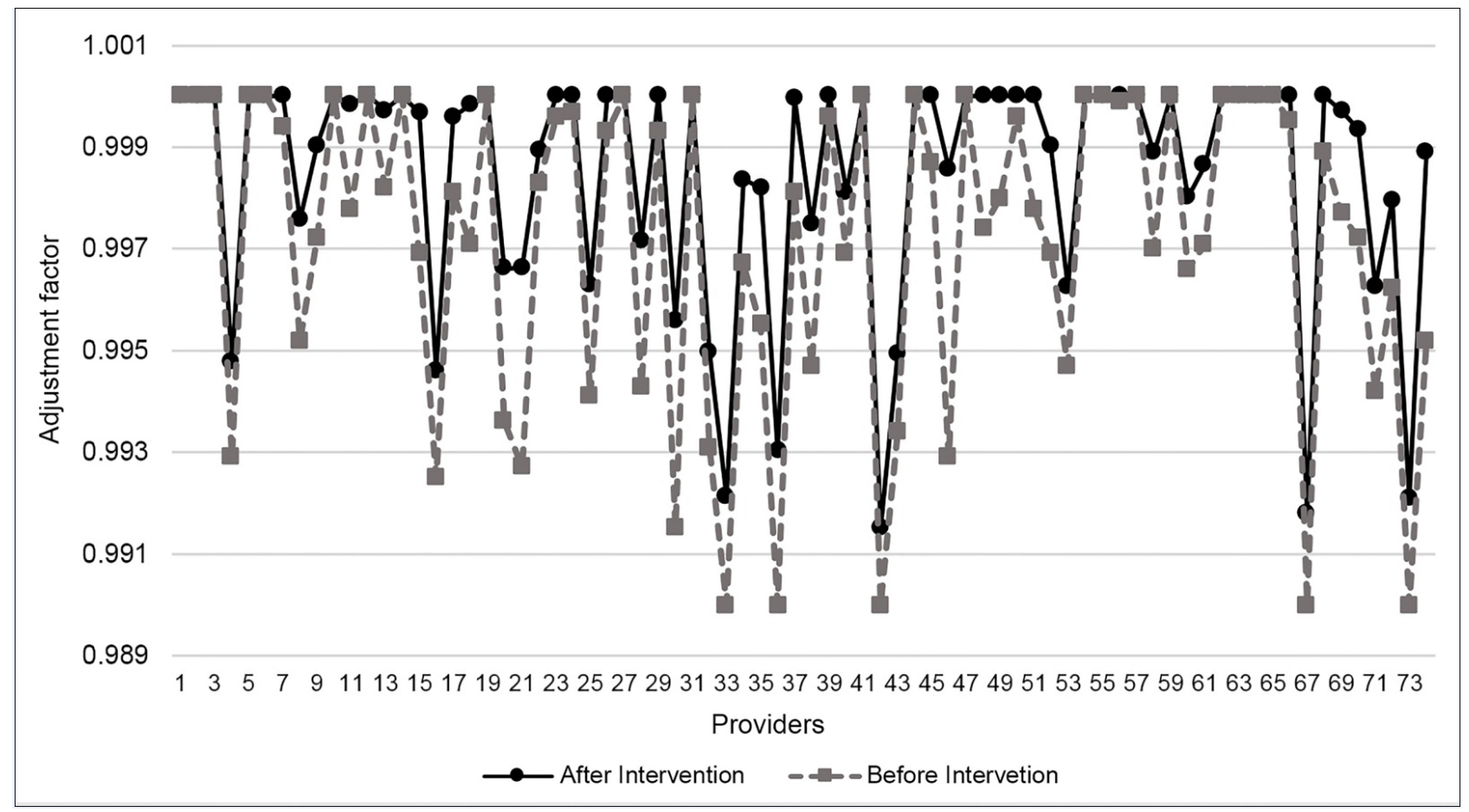

Figure 1. Adjustment ratio after and before the intervention

\section{Discussion}

A disease-specific intervention approach was presented as an alternative to HRRP, which is known to reduce preventable readmissions as well as to improve the quality of the delivery of care.

HRRP has been in place for three years and during that period the number of hospitals penalized has increased (see Table 6). The differences between FY2013 and FY2014 indicate that in FY2014, 11 more hospitals were penalized, while in FY2015, 413 more hospitals are penalized. These results would suggest that HRRP is not resulting in a decrease of readmission as the number of hospitals being penalized continues to increase. Conversely, a disease-specific intervention would immediately show progress by diminishing the risk of readmission for the patients, which would mean less hospitals being penalized. Results from the simulated scenario show that 710 hospitals are freed from penalties when implementing an intervention. When compared to the Published by Sciedu Press
HRRP results for FY2013-FY2014, the simulated intervention drastically outperforms the results of HRRP.

Table 6. History of penalties through the HRRP

\begin{tabular}{llll}
\hline Title & FY2013 & FY2014 & FY2015 \\
\hline $\mathrm{n}$ & 3,500 & 3,483 & 3,476 \\
Cap & $1 \%$ & $2 \%$ & $3 \%$ \\
Hospitals penalized & 2,214 & 2,225 & 2,638 \\
Average penalty & $0.42 \%$ & $0.38 \%$ & $0.62 \%$ \\
\hline
\end{tabular}

Furthermore, a comparison of the AF between the hospitals obtaining "better results" (lower penalty) and hospitals with "worse results" (higher penalty) under HRRP, show that the number of hospitals improving decreased, while the number of hospitals that worsen increased (see Table 7). This represents a contradiction when compared with the mission of CMS which is "better healthcare, better health and lower costs through improvement". ${ }^{[28]}$ A disease-specific inter- 
vention would ensure an improvement on readmission rates which would lead to, as explained by the current metrics, the number of hospitals being penalized to decrease.

Table 7. Evolution of hospitals' condition in HRRP

\begin{tabular}{lll}
\hline Title & FY2013-FY2014 & FY2014-FY2015 \\
\hline Got Worse & 1,054 & 2,024 \\
$\%$ & $31 \%$ & $59 \%$ \\
Got Better & 1,364 & 680 \\
$\%$ & $40 \%$ & $20 \%$ \\
\hline
\end{tabular}

Meanwhile, a consistent decrease in the excess of readmissions is reported for HF throughout FY2013-FY2015. AMI also shows a decrease in the readmission rate, but just during FY2013-FY2014, while in FY2014-FY2015 there is no improvement. Reductions are found to be inconsistent for
PN, as excess readmissions increased in FY2013-2014, and then decreased (see Table 8). The approach based on diseasespecific interventions shows an improvement on preventable readmissions.

Considering the short timeframe that HRRP has been active, results show small and inconsistent improvements in reducing readmissions. Furthermore, it has been said that economic penalties affect more those hospitals that provide care to vulnerable patients and institutions that take the responsibility to teach and train physicians. Results from the simulation show that an approach based on disease-specific interventions would be more appropriate than HRRP because: 1) it outperforms HRRP in reducing the readmission rates; 2) by its very nature improves the quality of the delivery of care; and 3) disease-specific interventions are less costly than the penalties from HRRP.

Table 8. Evolution of hospitals' condition in HRRP

\begin{tabular}{|c|c|c|c|c|c|c|c|c|c|}
\hline & AMI & & & HF & & & PN & & \\
\hline Fiscal Year rule & 2013 & 2014 & 2015 & 2013 & 2014 & 2015 & 2013 & 2014 & 2015 \\
\hline Number of cases & 500,931 & 492,346 & 505,702 & $1,193,210$ & $1,161,629$ & $1,154,060$ & 955,611 & 951,383 & 971,906 \\
\hline Average (SD) & $\begin{array}{l}0.648 \\
(.484)\end{array}$ & $\begin{array}{l}0.644 \\
(.484)\end{array}$ & $\begin{array}{l}0.644 \\
(.483)\end{array}$ & $\begin{array}{l}0.890 \\
(.324)\end{array}$ & $\begin{array}{l}0.888 \\
(.328)\end{array}$ & $\begin{array}{l}0.879 \\
(.334)\end{array}$ & $\begin{array}{l}0.894 \\
(.320)\end{array}$ & $\begin{array}{l}0.897 \\
(.315)\end{array}$ & $\begin{array}{l}0.892 \\
(.320)\end{array}$ \\
\hline Change & - & $-0.62 \%$ & $0 \%$ & - & $-0.22 \%$ & $-1.01 \%$ & - & $+0.34 \%$ & $-0.56 \%$ \\
\hline
\end{tabular}

Additionally, we presented several concerns with the methodology used by HRRP. Stone \& Hoffman in 2010 point out that since hospitals bill Medicare for each discharge, there is an incentive in maximizing the discharges. ${ }^{[14]}$ Moreover, reducing readmissions also reduces the hospital's revenue, which creates a conflict. A disease-specific intervention not only leads to better quality care but also translates into savings for hospitals. Increased quality of care will also lead to savings for patients as number of hospital readmissions decreases.

Joynt \& Jha in 2013 found that the effects of HRRP penalties would be more severe for large hospitals, teaching hospitals and safety net hospitals. ${ }^{[29]}$ Teaching hospitals represent about $25 \%$ of all participating hospitals in the IPPS. Therefore, it can be argued that the penalty approach may negatively impact the quality of medical education in the US. Instead, by applying disease-specific interventions, the quality of care for these patients improves, and avoids the negative financial impact on the hospitals. Furthermore, Berenson et al. in 2012 recognize that AMI, HF and PN represent about $12 \%$ of Medicare expenditures. ${ }^{[16]}$ This means that in the 2013 final rule, the $12 \%$ of Medicare admissions affected the reimbursement of all the admissions billed to Medicare through the IPPS. Since disease-specific interventions focus on improvement, say by targeting excessive preventable readmissions, it could eliminate the notion of applying across the board penalties.

Finally, Burgess \& Hockenberry in 2013 state that HRRP penalties will worsen the financial situation for those hospitals likely to be affected the most: large hospitals, teaching hospitals and safety net hospitals. ${ }^{[30]}$ Instead, the authors advise that a policy targeting the causes of the readmissions may produce better results. The implementation of diseasespecific interventions has the potential to address preventable readmissions from the mentioned perspective.

Key limitations of this study are: its short timeframe and the absence of patient-level data, which forced the use of aggregate data. Consequently, these results are not yet generalizable. However, the study does suggest (and reinforces) that an approach based on disease-specific interventions should lead to better results, better quality and less cost than HRRP. Another limitation of the this study was that the simulated scenario is applied to all hospitals, neglecting the idea that different hospitals might require different interventions. ${ }^{[5]}$ However, the authors believe that these initial results encourage further work in this direction.

Future work, in addition to addressing the limitations stated 
above, could also include other disease-specific interventions, considering the unique reality, characteristics and needs of specific hospitals (or cluster of hospitals). Granted this requires access to more granular, hospital/patient specific, data. Additionally, the implementation of disease-specific interventions should ideally be as patient centered as possible. It is very likely that to properly design, model and analyze these efforts researchers will require the development and implementation of probabilistic models or decision support systems, which include patient specific data. Consequently, having access to hospital and patient-level data will enable more realistic modeling and simulation strategies that would lead to stronger and more robust implementable conclusions.

\section{REFERENCES}

[1] World Health Organization. Global Health Expenditure Database. Global Health Expenditure Database. 2014.

[2] Tandon A, Murray C, Lauer J, et al. Measuring overall health systems performance for 191 countries. GPE Discussion paper series. World health organization. 2001; No. 30.

[3] Bloomberg. Most Efficient Health Care: Countries Bloomberg Best (and Worst). Most Efficient Health Care: Countries - Bloomberg Best (and Worst). Available from: http://www.bloomberg.com/visual-data/best-and-wor st/most-efficient-health-care-countries. (accessed Jul $7,2014)$

[4] Institute of Medicine. Best Care at Lower Cost: The Path to Continuously Learning Health Care in America. The National Academies Press. 2013.

[5] McAlister FA. Decreasing readmissions: it can be done but one size does not fit all. BMJ quality \& safety. 2013; 22(12): 975. http://dx.doi.org/10.1136/bmjqs-2013-002407

[6] Bisognano M, Boutwell A. Improving transitions to reduce readmissions. Front Health Serv Manage. 2009; 25(3): 3. PMid: 19382513.

[7] Berwick DM, Hackbarth AD. Eliminating waste in US health care. Journal of American Medical Association. 2012; 307(14): 1513. http://dx.doi.org/10.1001/jama.2012.362

[8] Kansagara D, Englander H, Salanitro A, et al. Risk Prediction Models for Hospital Readmission A Systematic Review. Journal of American Medical Association. 2011; 306(15): 1688. PMid: 22009101. http://dx.doi.org/10.1001/jama.2011.1515

[9] Bhalla R, Kalkut G. Could Medicare Readmission Policy Exacerbate Health Care System Inequity? Annals of Interval Medicine. 2010; 152(3): 114. PMid: 19949133. http://dx.doi.org/10.7326/0 003-4819-152-2-201001190-00185

[10] Jencks SF, Williams MV, Coleman EA. Rehospitalizations among patients in the Medicare fee-for-service program. The New England journal of medicine. 2009; 360(14): 1418. http://dx.doi.org/1 $0.1056 /$ NEJMsa0803563

[11] Robert Wood Johnson Foundation. The Revolving Door: A Report on U. S. Hospital Readmissions. 2013.

[12] Cutler D. How health care reform must bend the cost curve. Health affairs. 2010; 29(6): 1131. http://dx.doi.org/10.1377/hltha ff. 2010.0416

[13] Centers for Medicare \& Medicaid Services. ReadmissionsReduction-Program. Available from: http://www.cms.gov/Medi care/Medicare-Fee-for-Service-Payment/AcuteInpati entPPS/Readmissions-Reduction-Program.html. (accessed Jan 17, 2014)

[14] Stone J, Hoffman GJ. Medicare hospital readmissions: Issues, policy options and PPACA. 2010.
[15] Joynt KE, Jha AK. Characteristics of hospitals receiving penalties under the Hospital Readmissions Reduction Program. Journal of American Medical Association. 2013; 309(4): 342. http: //dx.doi.org/10.1001/jama.2012.94856

[16] Berenson RA, Paulus RA, Kalman NS. Medicare's readmissions - Reduction Program. A Positive Alternative. New England Journal of Medicine. 2012; 366(15): 1364. PMid: 22455754. http: //dx.doi.org/10.1056/NEJMp1201268

[17] Joynt KE, Jha AK. Thirty-day readmissions-truth and consequences. New England Journal of Medicine. 2012; 366(15): 1366. PMid: 22455752. http://dx.doi.org/10.1056/NEJMp1201598

[18] Russell L, Eller P. Acute Care Readmission Reduction Initiatives: Major Program Highlights. Center for Healthcare Research \& Transformation. 2013; pp 1-7.

[19] Cline CMJ, Israelsson BYA, Willenheimer RB, et al. Cost effective management programme for heart failure reduces hospitalisation. Heart. 1998; 80(5): 442. PMid: 9930041. http://dx.doi.org/1 $0.1136 / \mathrm{hrt} .80 .5 .442$

[20] Naylor MD, Brooten DA, Campbell RL, et al. Transitional care of older adults hospitalized with heart failure: a randomized, controlled trial. Journal of the American Geriatrics Society. 2004; 52(5): 675. http://dx.doi.org/10.1111/j.1532-5415.2004.52202.x

[21] Hernandez AF, Greiner MA, Fonarow GC, et al. Relationship between early physician follow-up and 30-day readmission among Medicare beneficiaries hospitalized for heart failure. Journal of American Medical Association. 2010; 303(17): 1716. PMid: 20442387. http://dx.doi.org/10.1001/jama.2010.533

[22] Grafft CA, McDonald FS, Ruud KL, et al. Effect of Hospital Follow-up Appointment on Clinical Event Outcomes and Mortality. Archives of Internal Medicine. 2010; 170(11): 955. PMid: 20548008 http://dx.doi.org/10.1001/archinternmed.2010.105

[23] Harrison PL, Hara PA, Pope JE, et al. The Impact of Postdischarge Telephonic Follow-Up on Hospital Readmissions. Population Health Management. 2011; 14(1): 27. http://dx.doi.org/10.1089/p op. 2009.0076

[24] Mullen C. Hospital System Readmissions. Journal of Purdue Undergraduate Research. 2012; 2: 42. http://dx.doi.org/10.5703/j pur.02.1.07

[25] Manning S. Bridging the Gap Between Hospital and Home A New Model of Care for Reducing Readmission Rates in Chronic Heart Failure. Journal of Cardiovascular Nursing. 2011; 26(5): 368 http://dx.doi.org/10.1097/JCN.0b013e318202b15c

[26] Bureau of Labor Statistics. May 2012 National Occupational Employment and Wage Estimates. Available from: http://www.bls.gov/ oes/current/oes_nat.htm\#29-0000. (accessed Mar 11, 2014)

[27] Centers for Medicare \& Medicaid Services. FY2013 Final Rule Data Files. Available from: http://www.cms.gov/Medicare/Medic are-Fee-for-Service-Payment/AcuteInpatientPPS/FY-2 013-IPPS-Final-Rule-Home-Page-Items/FY2013-Final-R 
ule-Data-Files .html?DLPage=1\&DLSort=0\&DLSortDir=a scending. (accessed Oct 23, 2014)

[28] Centers for Medicare \& Medicaid Services. Our Mission I Center for Medicare \& Medicaid Innovation. Available from: http://inno vation.cms.gov/about/Our-Mission/index.html. (accessed Jan 8, 2015)

[29] Joynt K, Jha A. Characteristics of hospitals receiving penalties under the Hospital Readmissions Reduction Program. JAMA. 2013; 309(4) 2013. PMid: 23340629. http://dx.doi.org/10.1001/jama. 20 12.94856

[30] Burgess JF, Hockenberry JM. Can all cause readmission policy improve quality or lower expenditures? A historical perspective on current initiatives. Health economics, policy, and law. 2013; 1 http://dx.doi.org/10.1017/S1744133113000340

[31] Holland R, Battersby J, Harvey I, et al. Systematic review of multidisciplinary interventions in heart failure. Heart (British Cardiac Society). 2005; 91(7): 899. http://dx.doi.org/10.1136/hrt .2004 .048389

[32] Jovicic A, Holroyd-Leduc JM, Straus SE. Effects of self-management intervention on health outcomes of patients with heart failure: a systematic review of randomized controlled trials. BMC cardiovascular disorders. 2006; 6: 43. http://dx.doi.org/10.1186/1471-2 261-6-43

[33] Phillips CO, Wright SM, Kern DE, et al. Comprehensive discharge planning with Postdischarge Support for Older Patients with congestive heart failure. Journal of American Medical Association. 2004 291(11): 1358. PMid: 15026403. http://dx.doi.org/10.1001 /jama.291.11.1358

[34] Roccaforte R, Demers C, Baldassarre F, et al. Effectiveness of comprehensive disease management programmes in improving clinical outcomes in heart failure patients. A meta-analysis. European journal of heart failure. 2005; 7(7): 1133. http://dx.doi.org/10.1016 /j.ejheart. 2005.08.005

[35] Chaudhry S, Mattera J, Curtis J, et al. Telemonitoring in patients with heart failure. The New England journal of medicine. 2010; 363(24): 2301. PMid: 21080835. http://dx.doi.org/10.1056/NEJMoa1 010029

[36] Fonarow GC, Stevenson LW, Walden JA, et al. Impact of a Comprehensive Heart Failure Management Program on Hospital Readmission and Functional Status of Patients With Advanced Heart Failure. Journal of American College of Cardiology. 1997; 30(3): 725. http://dx.doi.org/10.1016/S0735-1097 (97)00208-8
[37] Giordano A, Scalvini S, Zanelli E, et al. Multicenter randomised trial on home-based telemanagement to prevent hospital readmission of patients with chronic heart failure. International journal of cardiology. 2009; 131(2): 192. http://dx.doi.org/10.1016/j.ijcar d. 2007.10 .027

[38] Hansen LO, Greenwald JL, Budnitz T, et al. Project BOOST: effectiveness of a multihospital effort to reduce rehospitalization. Journal of hospital medicine. 2013; 8(8): 421. http://dx.doi.org/10. 1002/jhm. 2054

[39] Jack B, Chetty V, Anthony D, et al. A Reengineered Hospital Discharge Program to Decrease Rehospitalization: A randomized Trial. Annals of internal Medicine. 2009; 150(3): 178. PMid: 19189907. http://dx.doi.org/10.7326/0003-4819-1 50-3-200902030-00007

[40] Krumholz H, Amatruda J, Smith GL, et al. Randomized trial of an education and support intervention to preventreadmission of patients with heart failure. Journal of the American College of Cardiology. 2002; 39(1): 83. http://dx.doi.org/10.1016/S0735-1 097 (01) 01699-0

[41] Naylor MD, Brooten D, Campbell R, et al. Comprehensive Discharge Planning and Home Follow-up of Hospitalized Elders. Journal of American Medical Association. 1999; 281(7): 613. http: //dx.doi.org/10.1001/jama.281.7.613

[42] Rich M, Beckham V, Wittemberg C, et al. A multidisciplinary intervention to prevent the readmission of elderly patients with congestive heart failure. The New England journal of medicine. 1995; 333(18): 1190. PMid: 7565975. http://dx.doi.org/10.1056/NEJM199 511023331806

[43] Riegel B, Carlson B, Kopp Z, et al. Effect of a standardized nurse case-management telephone intervention on resource use in patients with chronic heart failure. Archives of Internal Medicine. 2002; 162: 705. PMid: 11911726. http://dx.doi.org/10.1001/archint e.162.6.705

[44] Stewart S, Pearson S, Horowitz JD. Effects of a home-based intervention among patients with congestive heart failure discharged from acute hospital care. Archives of Internal Medicine. 1998; 158: 1067. PMid: 9605777. http://dx.doi.org/10.1001/archinte.158. 10.1067

[45] Stewart S, Horowitz JD. Home-Based Intervention in Congestive Heart Failure: Long-Term Implications on Readmission and Survival Circulation. 2002; 105(24): 2861. http://dx.doi.org/10.1161 /01.CIR. 0000019067.99013 .67 